\title{
Article \\ How to Improve Customer Engagement in Social Networks: A Study of Spanish Brands in the Automotive Industry
}

\author{
Luis Matosas-López ${ }^{1}$ (D) and Alberto Romero-Ania ${ }^{2, *(D)}$ \\ 1 Department of Financial Economics and Accounting, Rey Juan Carlos University, 28933 Madrid, Spain; \\ luis.matosas@urjc.es \\ 2 Department of Applied Economics, Rey Juan Carlos University, 28933 Madrid, Spain \\ * Correspondence: alberto.romero@urjc.es
}

\section{check for} updates

Citation: Matosas-López, L.; Romero-Ania, A. How to Improve Customer Engagement in Social Networks: A Study of Spanish Brands in the Automotive Industry. J. Theor. Appl. Electron. Commer. Res. 2021, 16, 3269-3281. https://doi.org/ $10.3390 /$ jtaer16070177

Academic Editors: Inma

Rodríguez-Ardura and

Gisela Ammetller

Received: 23 October 2021

Accepted: 19 November 2021

Published: 23 November 2021

Publisher's Note: MDPI stays neutral with regard to jurisdictional claims in published maps and institutional affiliations.

Copyright: (c) 2021 by the authors. Licensee MDPI, Basel, Switzerland. This article is an open access article distributed under the terms and conditions of the Creative Commons Attribution (CC BY) license (https:/ / creativecommons.org/licenses/by/ $4.0 /)$.

\begin{abstract}
The objective of this research is to identify to what extent volumes, components, time slots, and publication topics improve customer engagement with Spanish automotive brands through social networks. The study considers thirteen brands and the total number of publications created by them in 2020 (23,670 publications) on the social network Twitter. Applying machine learning algorithms followed by multiple linear regression techniques, the authors examine how the variables previously mentioned affect a customer engagement indicator developed for this purpose. The results reveal that while publication components (links, mentions, and hashtags) and the publication time slot do not affect customer engagement, the volume of retweets made by the brand and publications on customer experience topics (without a direct commercial purpose) significantly improve the customer engagement indicator. The authors conclude that customer engagement in social networks can only be improved by conducting exhaustive analyses of activity data for these platforms. However, such analyses must not be done via generic multisector analyses, which only generate superficial and inapplicable knowledge, but rather through detailed studies for each sector.
\end{abstract}

Keywords: customer engagement; social networks; Twitter; automotive industry; machine learning algorithms; multiple linear regression

\section{Introduction}

The generalization of the use of social networks has created a new relational paradigm in our lives. This fact has led the academic community to examine these technologies from different perspectives. Some recurring topics of study include network structures [1], user characteristics [2], platform use patterns [3], motivations for platform use [4], user privacy [5], information security [6], and the risks to which the subject is exposed [7].

The information stored in social networks provides a vast record of daily thoughts and behaviors of individuals of all types and social conditions. In recent years, the messages of users of these platforms have been used to explore and forecast social and environmental issues of various kinds. Some examples include studies of the ideological polarization [8], the effect on political commitment [9], the social impact of religious influencers [10], the identification of environmental problems in certain areas [11], the development of social activism movements [12], predictions of economic fluctuations in stock exchange markets [13], the influence in the promotion of organizational development [14], and effects on corporate investment efficiency [15].

Within the business setting, the main value of social networks lies in their versatility and potential to facilitate communication [16]. Since these technologies first appeared in early 2000, platforms such as Twitter, Facebook, Instagram, and YouTube have been integrated into the strategies of many companies, becoming in many cases the cornerstone of their communication processes [17,18]. According to Richter et al. [19], within the business context, social networks have three main lines of application: (1) communication in personnel selection processes; (2) relationships in the work environment; and (3) interaction 
between companies and customers or potential customers. The present study follows this last line of research, focusing, in particular, on the concept of customer engagement and on how it can be improved.

\subsection{Customer Engagement in Social Networks}

The studies on the issue of customer engagement in social networks adopt different approaches [20,21]. Schau et al. [22] analyze the concept of added value, Chan and Li [23] examine emotional attachment to brands, Jahn and Kunz [24] focus on consumer loyalty, and Habibi et al. [25] explore trust building.

One of the most acknowledged approaches in the literature is that employed by Pansari and Kumar [26]. These authors provide a behavioral definition of customer engagement that involves two approaches: one that implies a material and direct contribution to the company and a second that involves an intangible and indirect contribution. The first is related to purchases, while the second is linked to influence and feedback. This second interpretation of customer engagement is the focus of the present study.

For this second behavioral approach, Giakoumaki and Krepapa [27] define customer engagement as the acknowledgement that the user grants a company publication through the platform's functionalities. More specifically, and according to different authors [28,29], this acknowledgement occurs when the subject shares, or marks as a favorite, content published by the company.

A non-systematic literature review on the topic of customer engagement through social networks provides endless references focused on the issue of influence and feedback. Table 1 shows a selection of the works that, in the authors' view, have been more influential in recent years. The selection of studies presented in Table 1 was made by the authors considering the publications that have had the greatest relevance in the period of the last eight years, taking into consideration their impact and citations volume in different databases. For each study, the platforms examined and the industry considered are indicated, in addition to the methodological approaches adopted and the analytic techniques used in each case.

Table 1. Studies on customer engagement in social networks.

\begin{tabular}{|c|c|c|c|c|}
\hline Author/s & Platform Considered & Industry/Sector & Methodological Approach & Technique Used \\
\hline $\begin{array}{l}\text { Pletikosa Cvijikj and } \\
\text { Michahelles [30] }\end{array}$ & Facebook & Food & Analysis of activity metrics & $\begin{array}{l}\text { Structural equation } \\
\text { modeling }\end{array}$ \\
\hline Hutter et al. [31] & Facebook & Automotive & Surveys & $\begin{array}{l}\text { Structural equation } \\
\text { modeling }\end{array}$ \\
\hline Aleti et al. [32] & Twitter & Beverage & Analysis of activity metrics & Multiple linear regression \\
\hline Balan [33] & Instagram & Sport & Analysis of activity metrics & Descriptive analysis \\
\hline $\begin{array}{l}\text { Abdullah and } \\
\text { Zolkepli [34] }\end{array}$ & $\begin{array}{c}\text { Facebook, Twitter, and } \\
\text { Instagram }\end{array}$ & Restoration & Analysis of activity metrics & Text-Data mining \\
\hline Mariani et al. [35] & Facebook & Tourism & Analysis of activity metrics & Multiple linear regression \\
\hline Saura et al. [36] & Twitter & Financial & Analysis of activity metrics & $\begin{array}{l}\text { Machine learning } \\
\text { algorithms }\end{array}$ \\
\hline $\begin{array}{l}\text { Giakoumaki and } \\
\text { Krepapa [27] }\end{array}$ & Instagram & Luxury & Surveys & Multiple linear regression \\
\hline Modi and Zhao [37] & Twitter and Instagram & Apparel & Analysis of activity metrics & $\begin{array}{l}\text { Machine learning } \\
\text { algorithms }\end{array}$ \\
\hline Lutfeali et al. [38] & Instagram & Food and beverage & Surveys & $\begin{array}{l}\text { Structural equation } \\
\text { modeling }\end{array}$ \\
\hline $\begin{array}{l}\text { Denktaş-Şakar and } \\
\text { Sürücü [39] }\end{array}$ & Facebook & Logistics & Analysis of activity metrics & Descriptive analysis \\
\hline $\begin{array}{c}\text { Paliwoda-Matiolanska } \\
\text { et al. [40] }\end{array}$ & Twitter & Energy & Analysis of activity metrics & Text-Data mining \\
\hline
\end{tabular}


Pletikosa Cvijikj and Michahelles [30] conducted one of the first studies to comprehensively analyze the phenomenon of customer engagement in social media. Taking as reference a set of food sector companies' Facebook pages, the authors examine how characteristics and types of content and the time of publication influence likes, comments, and shared publications. The authors, among other results, find that content related to entertainment and publications created on weekdays increase the number of likes and comments.

Hutter et al. [31] explore several issues related to the influence that the Facebook page of a major automotive brand has on its audience. The authors reveal that while there is a positive effect on consumer brand awareness, word of mouth, and purchase intentions, the resulting overload of information has a pernicious effect on engagement observed on the brand's fan page.

The study conducted by Aleti et al. [32] examines how the activity of a sample of beer industry companies on Twitter influences both retweeted content and the number of followers. The findings of this study indicate that even when the number of publications does not seem to have any effect on the user, the use of hashtags and mentions is significantly correlated with customer engagement.

Balan's research [33] explores how the content of a major sports equipment brand posted on Instagram influences customer engagement observed on the platform. The results of the study reveal the existence of significant differences in likes and comments received depending on the publication topic.

Abdullah and Zolkepli [34] analyze sentiment expressed by the publications of a well-known international group of coffee shops on Facebook, Twitter, and Instagram. The authors find that polarity in the sentiment of the brand's messages (through text or emoticons) conditions customer engagement and the company's relationship with its audience. The work also highlights a need to adapt these expressions of feeling to the specific protocols and formats of each platform.

In addition, Mariani et al. [35] examine how different organizations of the tourism sector in different countries use their Facebook accounts for the promotion of their destinations. The results show how customer engagement is improved through the use of photos and publications on weekends. Similarly, the results reveal that publications at night have a negative influence on the audiences of the accounts analyzed.

The work of Saura et al. [36] on financial sector companies' presence on Twitter yields interesting results on the possibility of analyzing the publications' sentiment in this platform. The authors show that although users tend to express frequently negative opinions of banking companies, this feedback can be used to address customer outreach actions.

Giakoumaki and Krepapa [27] examine how the content of luxury brands posted on Instagram can draw greater or lesser acceptance depending on whether the publication comes from one source or another. The authors confirm that customer engagement improves when the publication's source is a conventional user and not an influencer or the corporate company's account.

Modi and Zhao [37] similarly investigate customer engagement in the apparel industry, analyzing users' behavior on Twitter and Instagram. The findings in this research indicate that while Twitter network users are more sensitive to knowledge-based messages, Instagram users engage more easily with emotion-driven publications.

Lutfeali et al. [38] explore how adolescents' willingness to engage with food and beverage brands' ads on Instagram is conditioned by the number of likes previously identified in the publication. The study reveals that adolescents rated ads with a high number of likes better than ads with fewer likes, demonstrating the influence of social norms in shaping engagement behavior.

The study conducted by Denktaş-Şakar and Sürücü [39] examines the relationship between stakeholders and international logistic companies on Facebook, in one of the few investigations focused on the concept of business-to-business (B2B) engagement. The 
authors identify that vivid publications contribute to strengthen the online relationship between organizations, removing the geographic and cultural barriers in this sector.

Finally, Paliwoda-Matiolanska et al. [40] analyze, in the energy sector, the use of Twitter as a mechanism to engage with a firm's stakeholders in the context of Corporate Social Responsibility (CSR) strategies. The study demonstrates that energy companies apply, in general terms, a defensive branding discourse, in addition to a semantic narrative that indicates a limited orientation towards CSR.

The referenced studies reveal the wide variety of industries previously analyzed in the literature. Examples of this are the food, sport, tourism, finance, apparel, and energy industries $[30,33,35,36,40]$.

Regarding methodological approaches, although studies focusing on the platform activity metrics predominate [35,37], there is also research supported by surveys $[27,38]$. Finally, techniques used range from simple descriptive analyses [39] to complex techniques supported by the application of machine learning algorithms [36].

This review corroborates what was found in the systematic literature review on brand strategies in social networks carried out by Cuevas-Molano et al. [41]. This study, in which the authors examined publications indexed in the Web of Science (WOS) over the last fourteen years, underlines the heterogeneity of the research carried out in this field.

\subsection{Objectives}

The issue of customer engagement in social networks is a mature and consolidated topic of study; nevertheless, how such engagement can be improved is still under study and debate. The dynamic and changing nature of these technologies forces companies and brands to periodically analyze the data generated by these platforms to extract the knowledge hosted by them. The millions of interactions that daily occur on social networks between companies and users generate an enormous volume of information that can be analyzed [42]. These data make it possible to study customer engagement in great depth. However, this information is not always used adequately.

In addition, models that serve to predict customer engagement in social media are not uniform and ubiquitous but vary by industry or sector and are, consequently, based on the organization's audience [43]. For example, although certain patterns may be observed across industries with similar audiences, it also seems logical to assume that customer engagement in the food sector should not be conditioned by the same variables that affect engagement in the luxury brand industry.

The present research sheds light on the improvement of customer engagement on social networks. In this sense, the authors set as the research objective, and primary purpose of investigation, the identification of the variables that can improve customer engagement in the automotive industry in Spain. In the indicated framework, the authors analyze how volumes, components, time slots, and publication topics increase customer engagement. This study therefore answers the following four research questions.

RQ1: To what extent do publication volumes affect customer engagement through social networks?

$\mathrm{RQ2}$ : To what extent do publication components affect customer engagement through social networks?

RQ3: To what extent do publication time slots affect customer engagement through social networks?

RQ4: To what extent do publication topics affect customer engagement through social networks?

\section{Materials and Methods}

\subsection{Sample Design and Data Extraction}

The authors took as the object of study the automotive industry in Spain and Twitter as the social network platform to be monitored. The companies were selected, in accordance 
with Balan [33], based on the Best Global Brands ranking designed by the international consulting firm Interbrand [44].

Of the hundred companies considered in the indicated ranking, fifteen brands belong to the automotive industry. After screening out those that do not have active accounts specifically oriented toward the Spanish market, thirteen brands were maintained. These brands are Audi, BMW, Ford, Honda, Hyundai, Kia Motors, Land Rover, Mercedes Benz, Mini, Nissan, Porsche, Toyota, and Volkswagen.

Once the sampling elements were selected, all content published by the official accounts of the thirteen companies in 2020 was extracted from the Twitter platform. Data extraction, following the procedure recommended by other authors [45-47], was performed through the Twitter API by using the service provider Twitonomy. This process yielded 23,670 publications.

\subsection{Data Screening and Construction of Variables}

The compiled dataset was stored for screening. The authors extracted from the dataset twenty-seven variables organized into five categories: (a) publication volumes; (b) publication components; (c) publication time slots; (d) publication topics; and (e) observed customer engagement (see Table 2). Categories (a), (b), (c), and (d) gather the indicators used as independent variables in the study. The single indicator in category (e) was used as a dependent variable in the analysis.

Table 2. Variables extracted from the dataset.

\begin{tabular}{lcl}
\hline \multicolumn{1}{c}{ Categories } & $\begin{array}{c}\text { Num. of } \\
\text { Variables }\end{array}$ & \multicolumn{1}{c}{ Names of Variables } \\
\hline (a) Publication volumes & 4 & Daily Tweets, Original Tweets, Retweets, Replies \\
\hline (b) Publication components & 7 & $\begin{array}{l}\text { Tweets with Mentions, Tweets with Links, } \\
\text { Tweets with Hashtags, Tweets with Mentions } \\
\text { and Links, Tweets with Mentions and Hashtags, } \\
\text { Tweets with Links and Hashtags, Tweets with } \\
\text { Mentions, Links and Hashtags }\end{array}$ \\
\hline (c) Publication time slots & 8 & $\begin{array}{l}\text { Pub. from 8:00 to 10:59, Pub. from 11:00 to 13:59, } \\
\text { Pub. from 14:00 to 16:59, Pub. from 17:00 to 19:59, } \\
\text { Pub. from 2:00 to 4:59, Pub. from 5:00 to 7:59 }\end{array}$ \\
\hline Total & 7 & $\begin{array}{l}\text { Pub. of each of the seven topics indicated in the } \\
\text { following section (Section 2.2.1) }\end{array}$ \\
\hline $\begin{array}{l}\text { (d) Publication topics } \\
\text { engagement }\end{array}$ & 1 & Indicator of customer engagement \\
\hline
\end{tabular}

Source: The authors.

\subsubsection{Independent Variables}

The variables of categories (a), (b), and (c) were created from the postulates of studies such as those of Pletikosa Cvijikj and Michahelles [30], Aleti et al. [32], and Hanifawati et al. [48]. These variables require only basic screening tasks. However, creating the category (d) variables, which reflect publication topics, required more complex processing. For the constitution of category (d) variables, each message of the dataset was classified into a publication topic. This categorization of the text of messages, in line with previous studies $[34,36]$, was carried out using a machine learning algorithm.

According to Hsu [49], machine learning algorithms can be of two fundamental types: supervised and unsupervised. For the first, there is an initial set of data of a small scale, in which each record has already been labeled by the researcher with input-output pairs to facilitate model training. From this initial dataset, the algorithm learns to assign the appropriate output label to each incoming element. For the second, there is no set of data 
already labeled, nor is there a training process for the model. In this case, the algorithm establishes input-output pairs without prior knowledge, resulting in a more imprecise categorization [50]. Regarding the techniques used by machine learning algorithms, these include the naïve Bayes classifier, decision trees, random forest algorithms, and support vector machines [51].

In this case, the authors applied a supervised learning algorithm using the support vector machine technique. The support vector machine technique allows for the categorization of each message according to the central topic of the publication. This categorization, in line with previous research [34,52], was performed through the text classification API of the MonkeyLearn library.

After carrying out the training process by manually categorizing 400 publications, the authors identified seven different topics: product or brand advertising; promoted events (motor, sport, music, etc.); launch of new products/services; contests and participatory activities; fairs, forums, and shows; customer experiences (without a direct commercial purpose); and technological research, development, and innovation $(\mathrm{R}+\mathrm{D}+\mathrm{I})$. Once the publication topics were identified and the machine learning algorithm training was completed, it had the necessary experience to classify the texts of each of the 23,670 publications extracted into the topics indicated.

Once the text classification was completed, following the recommendations of other authors [36], Krippendorff's alpha was used to measure the accuracy of the categorization performed by the machine learning algorithm. The Krippendorff alpha value obtained (0.807) indicates that the machine learning algorithm carried out a sufficiently precise classification.

\subsubsection{Dependent Variable}

Variable (e), the variable used to measure customer engagement, was designed according to the postulates of previous studies $[28,29]$ using as a reference the number of retweets and favorites that brand publications generate in their audiences. To define this variable, the researchers took as a guide the proposals of studies such as those of Oviedo-García [53] and Pletikosa Cvijikj and Michahelles [30]. Considering the outcomes of these studies, the customer engagement indicator was set as the sum of retweets and favorites divided, firstly, by the number of publications and, secondly, by the account audience. The formula of the customer engagement indicator is presented below:

$$
\left[\frac{\text { RT obtained }+ \text { FV obtained }}{\text { Total publications }}\right] / \text { Audience of the account }
$$

The RT and FV values obtained represent the number of times that the company's publications have been shared and/or marked as favorites by its audience in the period under study. The total number of publications corresponds to the sum of tweets, retweets, and replies made from the account in the period analyzed. Finally, the account audience is represented by the number of direct brand followers at the time of data extraction.

The correction of retweets and favorites obtained considering first the total number of messages published on the account and second the number of followers allows us to obtain a better-adjusted indicator of customer engagement, minimizing the impact of potential fluctuations in brand activity on the platform.

\subsection{Data Analysis}

To answer the proposed research questions, in accordance with previous studies [27,35], the authors applied an analysis of multiple linear regression. To examine the explanatory power of each independent variable, the items of each of the four categories were introduced into the predictive model as individual indicators. The researchers applied here the stepwise method for incorporating variables during the analysis. Once the multiple linear regression analysis was completed, the authors corroborated the validity of the regression model obtained. For this purpose, in accordance with Matosas-López and 
Romero-Ania [54], the regression residuals were analyzed using, on the one hand, the Shapiro-Wilk test, and on the other, the Durbin-Watson test.

\section{Results}

The results of the multiple linear regression analysis show the existence of a model in which only two of the 26 considered independent variables have a significant influence on the dependent variable, represented by the customer engagement indicator (see Table 3).

Table 3. Multiple linear regression coefficients.

(e) Observed Customer Engagement

\begin{tabular}{|c|c|c|c|}
\hline & $\beta$ & $\mathbf{t}$ & Sig. $p$-Value \\
\hline \multicolumn{4}{|l|}{ (a) Publication volumes } \\
\hline Daily tweets & 0.033 & 0.214 & 0.835 \\
\hline Original tweets & 0.266 & 1.721 & 0.116 \\
\hline Retweets & 0.745 & 4.029 & 0.049 * \\
\hline Replies & -0.284 & -2.097 & 0.062 \\
\hline \multicolumn{4}{|l|}{ (b) Publication components } \\
\hline Tweets with Mentions & -0.191 & -1.477 & 0.170 \\
\hline Tweets with Links & 0.208 & 1.674 & 0.125 \\
\hline Tweets with Hashtags & 0.198 & 1.588 & 0.143 \\
\hline Tweets with Mentions and Links & 0.024 & 0.154 & 0.881 \\
\hline Tweets with Mentions and Hashtags & 0.017 & 0.112 & 0.913 \\
\hline Tweets with Links and Hashtags & 0.201 & 1.607 & 0.139 \\
\hline Tweets with Mentions, Links, and Hashtags & 0.072 & 0.482 & 0.64 \\
\hline \multicolumn{4}{|l|}{ (c) Publication time slots } \\
\hline Pub. from 8:00 to 10:59 & -0.003 & -0.022 & 0.983 \\
\hline Pub. from 11:00 to $13: 59$ & -0.074 & -0.479 & 0.642 \\
\hline Pub. from 14:00 to $16: 59$ & -0.087 & -0.630 & 0.543 \\
\hline Pub. from 17:00 to $19: 59$ & -0.053 & -0.381 & 0.712 \\
\hline Pub. from 20:00 to $22: 59$ & 0.136 & 1.020 & 0.332 \\
\hline Pub. from 23:00 to 1:59 & 0.215 & 1.769 & 0.107 \\
\hline Pub. from 2:00 to 4:59 & 0.16 & 1.122 & 0.288 \\
\hline Pub. from 5:00 to 7:59 & 0.174 & 1.340 & 0.210 \\
\hline \multicolumn{4}{|l|}{ (d) Publication topics } \\
\hline Pub. Product or brand advertising & -0.153 & -0.360 & 0.726 \\
\hline Pub. Promoted events (motor, sport, music, etc.) & -0.015 & -0.042 & 0.968 \\
\hline Pub. Launch of new products/services & -0.24 & -0.588 & 0.570 \\
\hline Pub. Contests and participatory activities & -0.454 & -1.207 & 0.255 \\
\hline Pub. Fairs, forums, and shows & 0.258 & 0.773 & 0.457 \\
\hline $\begin{array}{l}\text { Pub. Customer experiences (without a direct } \\
\text { commercial purpose) }\end{array}$ & 0.898 & 6.758 & $0.000 * *$ \\
\hline $\begin{array}{l}\text { Pub. Technological research, development, and } \\
\text { innovation }(R+D+I)\end{array}$ & -0.357 & -0.734 & 0.480 \\
\hline
\end{tabular}

During the analysis, the item "Retweets" $(\beta=0.745, p<0.05)$ was entered in the first step of the procedure. The variable "Customer experiences (without a direct commercial purpose)" ( $\beta=0.898, p<0.0001)$ was added in the second step. These two items form a model that is significant as a whole $(\mathrm{F}=45.668, p<0.0001)$ and adequately explains the variance in the dependent variable with values of $R=0.898$ and $R^{2}=0.806$. Therefore, the model shows the impact of the variables "Retweets" and "Customer experiences (without a direct commercial purpose)" when predicting customer engagement.

To confirm the validity of the described regression, the authors analyzed its residual using the Shapiro-Wilk and Durbin-Watson tests. The Shapiro-Wilk test shows whether the values of the standardized residuals follow a normal distribution. The $p$-value above $0.05(p=0.801)$ confirms that the residuals are normally distributed [55]. The Durbin- 
Watson test is used to determine whether the assumption of residual independence is met. The indicator's value of between 1 and 3 (1.329) verifies that the residual independence requirement is satisfied [56]. The values obtained from both tests allow us to confirm that the model obtained is adequate and robust.

Since "Customer experiences (without a direct commercial purpose)" presents a $p$-value of $<0.0001$, being the most significant factor on customer engagement, the authors also carried out a descriptive analysis of the variables collected in category (d) Publication topics. This analysis includes not only the publication frequency of the topics but also the average number of retweets and favorites generated by messages on each topic (see Table 4).

Table 4. Descriptive analysis of variables on category (d) Publication topics.

\begin{tabular}{|c|c|c|c|}
\hline (d) Publication Topics & $\%$ of Total Tweets & $\begin{array}{l}\text { Average RT Received } \\
\text { Per Pub. }\end{array}$ & $\begin{array}{l}\text { Average FV Received } \\
\text { Per Pub. }\end{array}$ \\
\hline Pub. Product or brand advertising & $30.00 \%$ & 8.14 & 16.71 \\
\hline Pub. Promoted events (motor, sport, music, etc.) & $27.93 \%$ & 12.19 & 42.30 \\
\hline Pub. Launch of new products/services & $13.45 \%$ & 7.60 & 17.85 \\
\hline Pub. Contests and participatory activities & $12.41 \%$ & 11.33 & 28.50 \\
\hline Pub. Fairs, forums, and shows & $6.21 \%$ & 4.22 & 13.00 \\
\hline $\begin{array}{l}\text { Pub. Customer experiences (without a direct } \\
\text { commercial purpose) }\end{array}$ & $5.17 \%$ & 10.08 & 38.56 \\
\hline $\begin{array}{l}\text { Pub. Technological research, development, and } \\
\text { innovation }(\mathrm{R}+\mathrm{D}+\mathrm{I})\end{array}$ & $4.83 \%$ & 7.43 & 26.71 \\
\hline Total & $100.00 \%$ & & \\
\hline
\end{tabular}

\section{Source: The authors.}

Table 4 shows that of the seven thematic categories, the topics "Product or brand advertising" and "Promoted events (motor, sport, music, etc.)" are the most frequent, accounting for $30.00 \%$ and $27.93 \%$ of the messages, respectively. The exploration of retweet and favorite frequencies shows differences in how the content of each topic is recognized by the audience. The content generating the most interactions is related to promoted events (motor events, sports, music, etc.), contests and participatory activities, and customer experiences (without a direct commercial purpose).

\section{Discussion}

While it is true that this study is not the first to address the issue of customer engagement in social networks within the automotive industry, the present work provides an updated view of the field under study. The most relevant studies conducted in this field, that of Hutter et al. [31] on a well-known German brand and that of Tafesse [29] on five British brands, both focused on Facebook, were published in 2013 and 2015, respectively.

Likewise, even though a substantial number of studies have examined the activities carried out by companies and individuals on social networks, these investigations tend to focus exclusively on content characteristics (volumes, components, and publication time slots) $[57,58]$ or on message characteristics (tone, feeling, or publication topic) $[59,60]$. However, few studies have examined both topics simultaneously.

Perhaps the most representative work in this sense is the study by Pletikosa Cvijikj and Michahelles [30]. Their paper, similar to the present work, considers the characteristics of both content (volumes, components, and publication time slots) and messages (publication topics). However, the current study improves the work of Pletikosa Cvijikj and Michahelles in three ways. First, this study analyzes a significantly larger dataset. Second, Pletikosa Cvijikj and Michahelles apply a content classification considering three topics (information, entertainment, and rewards) contrasting to the seven topics considered here. Finally, Pletikosa Cvijikj and Michahelles consider only two publication time slots (peak and off-peak hours), while eight time slots are examined here. 
In addition, the present work contemplates a time horizon that is significantly broader than that considered by previous studies of this nature. While other works consider posts made over two weeks [34,61] or a month [33], the present study covers the publications of the selected companies over a one-year period.

\section{Answers to the Posed Research Questions}

The results obtained allow us to answer the four research questions posed. RQ1 and RQ4, those related to publication volumes and publication topics, are answered in a positive way. On the contrary, RQ2 and RQ3, which concern publication components and publication time slots, obtain a negative answer. The analysis reveals that customer engagement, although conditioned by the volume and topic of brand messages, does not seem to be influenced by message components or publication time slots.

Regarding the publication volumes, the results reveal that a larger number of retweets by the brand improves the indicator of customer engagement considered. This finding is in line with the results of studies such as those of Laudano et al. [62] and Chen [28]. Their research emphasizes that a greater volume of media activity favors connectivity with users.

Concerning publication topics, the results reveal that messages on customer experiences (without a direct commercial purpose) affect observed engagement levels. Equally, the descriptive exploration of average numbers of retweets and favorites obtained by a publication topic corroborates that publications of the aforementioned topic generate more interactions (in terms of average numbers of retweets and favorites). These results confirm the findings of Pletikosa Cvijikj and Michahelles [30] and Balan [33], showing that the thematic line of publication used by a company can condition the acknowledgement of messages received.

However, the results obtained here also seem to contradict what other authors have found, especially with regard to publication components and publication time slots [32,63]. Aleti et al. [32] show that a correct exploitation of publication components, such as hashtags and mentions, significantly improves customer engagement. Sabate et al. [63], on the other hand, regarding publication time slots, conclude that messages published during business hours are more likely to receive comments and therefore that publication time influences the amount of interactions.

In the authors' opinion, discrepancies between the findings of this research and the aforementioned studies may be due not only to intrinsic differences in the industries analyzed and the different profiles of audiences, but also to possible behavioral changes in platform response patterns. While Aleti et al. [32] and Sabate et al. [63] studied the beverage and tourism industries, respectively, the present research studies brands belonging to the automotive sector. Additionally, the above studies were published in 2016 and 2014 while the present work reflects media behavior at the present time. In this regard, according to the contributions of Feng et al. [64] on the evolution of the use of social media, such differences may be attributable to changes in user behavior in recent years.

\section{Conclusions}

The present study reveals that although the publication components (links, mentions, and hashtags) and publication time slots of messages do not seem to affect customer engagement, the volume of brand activity and publication topics do. Regarding publication volumes, content dissemination through retweets (either its own content or external content) has a positive impact on the indicator of customer engagement. Regarding publication topics, the findings show that messages about experiences (without a direct commercial purpose) also improve customer engagement.

Although both aspects have a significant impact on customer engagement, the second one, related to publication topics, shows the most significant influence. This finding is especially interesting, since the indicated topic, despite being the one with a greater impact on the customer engagement indicator analyzed, represents a relatively small portion of publications. The descriptive exploration of topics finds only 5.17\% of messages to focus on 
this topic. Instead, the analyzed companies focus their messages more heavily on product or brand advertising.

In the authors' opinion, such use of messages with commercial objectives has a saturation effect on the audience. While such saturation limits the effectiveness of advertising actions, it also improves customer acceptance of messages from which the user does not perceive a commercial objective, leading such messages to positively influence customer engagement. This situation demonstrates the importance of media professionals being able to identify topics of interest in their audiences and to adapt brand content to these preferences.

\subsection{Managerial or Practical Implications}

In view of the above, the authors point out that the findings reveal the existence of the following managerial implications. Digital marketing professionals should take these managerial implications into consideration when implementing social media strategies.

- The study confirms the need for social media professionals to perform detailed analyses on the aspects that influence customer engagement within the sector in which their company operates.

- Variables such as volumes, components, time slots, and, of course, publication topics should be analyzed, but not through generic multisector analyses that lead to merely superficial and inapplicable knowledge but with exhaustive and detailed examinations for each sector.

- Sectorial analyses enable us to extract underlying knowledge from each medium and for each industry. This knowledge may serve as a basis for decision-making processes that improve customer engagement with brands in each sector.

\subsection{Limitations and Future Lines of Study}

Although the authors analyze in depth the variables that influence customer engagement, the present study is not without limitations. The paper focuses exclusively on companies in the automotive industry in Spain, limiting the findings obtained to this geographical area. This limitation, which is intrinsic to any study of this type, also highlights avenues for further research.

In this sense, several lines for future action should be pointed out. The first is the analysis of this phenomenon in social media accounts of the automotive sector in different countries [65]. Although it is common for international brands such as those analyzed here to have global accounts, it is also true that in countries with large markets, these accounts coexist with the local accounts of the brand.

Secondly, in addition to our exploration of customer engagement in Spain within the automotive industry on Twitter, it would be advisable to analyze behaviors of the audiences of these companies on other social networks [66]. Codes of conduct and usage patterns on Twitter may differ from those of platforms such as Facebook or Instagram. Therefore, future studies should investigate whether the variables that influence customer engagement are consistent across platforms.

Finally, the premises of this study could serve as a basis for future research on the differences of customer engagement depending on the publication source. Comparing, for instance, the customer engagement generated when the content is posted by an influencer with the engagement obtained when the messages are published and directly promoted for the brand or company [67].

The exploration of these avenues of study would not only strengthen the knowledge generated by the present study but also enrich this field of research. Their findings would undoubtedly benefit both academics and professionals focused on the study and management of these platforms. 
Author Contributions: Conceptualization, methodology, formal analysis, investigation, data curation, writing —original draft, project administration, L.M.-L.; Investigation, project administration, validation, writing-review and editing, supervision, A.R.-A. All authors have read and agreed to the published version of the manuscript.

Funding: This research received no external funding.

Institutional Review Board Statement: Not applicable.

Informed Consent Statement: Not applicable.

Conflicts of Interest: The authors declare no conflict of interest.

\section{References}

1. Caci, B.; Cardaci, M.; Tabacchi, M.E. Facebook as a Small World: A topological hypothesis. Soc. Netw. Anal. Min. 2012, 2, 163-167. [CrossRef]

2. Bhattacharyya, P.; Garg, A.; Wu, S.F. Analysis of user keyword similarity in online social networks. Soc. Netw. Anal. Min. 2011, 1, 143-158. [CrossRef]

3. Gómez-García, M.; Matosas-López, L.; Palmero-Ruiz, J. Social Networks Use Patterns among University Youth: The Validity and Reliability of an Updated Measurement Instrument. Sustainability 2020, 12, 3503. [CrossRef]

4. Tarullo, R. ¿Por qué los y las jóvenes están en las redes sociales? Un análisis de sus motivaciones a partir de la teoría de usos y gratificaciones. Prism. Soc. 2020, 29, 222-239.

5. Alvertis, I.; Biliri, E.; Lampathaki, F.; Askounis, D. Social Agents to Enable Pervasive Social Networking Services. J. Theor. Appl. Electron. Commer. Res. 2018, 13, 50-84. [CrossRef]

6. Zhu, G.; Liu, H.; Feng, M. Sustainability of Information Security Investment in Online Social Networks: An Evolutionary Game-Theoretic Approach. Mathematics 2018, 6, 177. [CrossRef]

7. Calvete, E.; Orue, I.; Estévez, A.; Villardón, L.; Padilla, P. Cyberbullying in adolescents: Modalities and aggressors' profile. Comput. Human Behav. 2010, 26, 1128-1135. [CrossRef]

8. Masroor, F.; Khan, Q.N.; Aib, I.; Ali, Z. Polarization and Ideological Weaving in Twitter Discourse of Politicians. Soc. Media + Soc. 2019, 5, 1-14. [CrossRef]

9. Kizgin, H.; Jamal, A.; Rana, N.; Dwivedi, Y.; Weerakkody, V. The impact of social networking sites on socialization and political engagement: Role of acculturation. Technol. Forecast. Soc. Chang. 2019, 145, 503-512. [CrossRef]

10. Beta, A.R. Commerce, piety and politics: Indonesian young Muslim women's groups as religious influencers. New Media Soc. 2019, 21, 2140-2159. [CrossRef]

11. Chen, J.; Chen, H.; Hu, D.; Pan, J.Z.; Zhou, Y. Smog disaster forecasting using social web data and physical sensor data. In Proceedings of the IEEE International Conference on Big Data, IEEE Big Data 2015; Institute of Electrical and Electronics Engineers Inc.: Piscataway, NJ, USA, 2015; pp. 991-998.

12. Agur, C.; Frisch, N. Digital Disobedience and the Limits of Persuasion: Social Media Activism in Hong Kong's 2014 Umbrella Movement. Soc. Media Soc. 2019, 5, 1-12. [CrossRef]

13. Li, Q.; Zhou, B.; Liu, Q. Can twitter posts predict stock behavior? A study of stock market with twitter social emotion. In Proceedings of the IEEE International Conference on Cloud Computing and Big Data Analysis (ICCCBDA 2016), Chengdu, China, 5-7 July 2016; Institute of Electrical and Electronics Engineers Inc.: Chengdu, China, 2016; pp. 359-364.

14. Palacios-Marqués, D.; Gallego-Nicholls, J.F.; Guijarro-García, M. A recipe for success: Crowdsourcing, online social networks, and their impact on organizational performance. Technol. Forecast. Soc. Chang. 2021, 165, 120566. [CrossRef]

15. Yang, X.; Cao, D.; Andrikopoulos, P.; Yang, Z.; Bass, T. Online social networks, media supervision and investment efficiency: An empirical examination of Chinese listed firms. Technol. Forecast. Soc. Chang. 2020, 154, 119969. [CrossRef]

16. Zerfass, A.; Tench, R.; Verhoeven, P.; Verčič, D.; Moreno, Á. European Communication Monitor 2020; European Public Relations Education and Research Association: Brussels, Belgium, 2020.

17. Leek, S.; Houghton, D.; Canning, L. Twitter and behavioral engagement in the healthcare sector: An examination of product and service companies. Ind. Mark. Manag. 2019, 81, 115-129. [CrossRef]

18. Juntunen, M.; Ismagilova, E.; Oikarinen, E.L. B2B brands on Twitter: Engaging users with a varying combination of social media content objectives, strategies, and tactics. Ind. Mark. Manag. 2020, 89, 630-641. [CrossRef]

19. Richter, D.; Riemer, K.; vom Brocke, J. Internet Social Networking. Bus. Inf. Syst. Eng. 2011, 3, 89-101. [CrossRef]

20. Vinerean, S.; Opreana, A. Measuring Customer Engagement in Social Media Marketing: A Higher-Order Model. J. Theor. Appl. Electron. Commer. Res. 2021, 16, 16070145. [CrossRef]

21. Sajjad, M.; Zaman, U. Innovative perspective of marketing engagement: Enhancing users' loyalty in social media through blogging. J. Open Innov. Technol. Mark. Complex. 2020, 6, 93. [CrossRef]

22. Schau, H.J.; Muñiz, A.M.; Arnould, E.J. How Brand Community Practices Create Value. J. Mark. 2009, 73, 30-51. [CrossRef]

23. Chan, K.W.; Li, S.Y. Understanding consumer-to-consumer interactions in virtual communities: The salience of reciprocity. J. Bus. Res. 2010, 63, 1033-1040. [CrossRef]

24. Jahn, B.; Kunz, W. How to transform consumers into fans of your brand. J. Serv. Manag. 2012, 23, 344-361. [CrossRef] 
25. Habibi, M.R.; Laroche, M.; Richard, M.O. The roles of brand community and community engagement in building brand trust on social media. Comput. Human Behav. 2014, 37, 152-161. [CrossRef]

26. Pansari, A.; Kumar, V. Customer engagement: The construct, antecedents, and consequences. J. Acad. Mark. Sci. 2017, 45, 294-311. [CrossRef]

27. Giakoumaki, C.; Krepapa, A. Brand engagement in self-concept and consumer engagement in social media: The role of the source. Psychol. Mark. 2019, 37, 457-465. [CrossRef]

28. Chen, G.M. Tweet this: A uses and gratifications perspective on how active Twitter use gratifies a need to connect with others. Comput. Human Behav. 2011, 27, 755-762. [CrossRef]

29. Tafesse, W. Content strategies and audience response on Facebook brand pages. Mark. Intell. Plan. 2015, 33, 927-943. [CrossRef]

30. Pletikosa Cvijikj, I.; Michahelles, F. Online engagement factors on Facebook brand pages. Soc. Netw. Anal. Min. 2013, 3, 843-861. [CrossRef]

31. Hutter, K.; Hautz, J.; Dennhardt, S.; Füller, J. The impact of user interactions in social media on brand awareness and purchase intention: The case of MINI on Facebook. J. Prod. Brand Manag. 2013, 22, 342-351. [CrossRef]

32. Aleti, T.; Harrigan, P.; Cheong, M.; Turner, W. An investigation of how the Australian brewing industry influence consumers on Twitter. Australas. J. Inf. Syst. 2016, 20, 1-20. [CrossRef]

33. Balan, C. Nike on Instagram: Themes of branded content and their engagement power. In Proceedings of the CBU International Conference, Pragure, Czech Repulic, 17 March 2021; Central Bohemia University: Prague, Czech Republic, 2017; Volume 5, pp. 13-18.

34. Abdullah, N.S.D.; Zolkepli, I.A. Sentiment analysis of online crowd input towards brand provocation in facebook, twitter, and instagram. In Proceedings of the ACM International Conference, Glasgow, Scotland, 13-17 November 2017; Association for Computing Machinery: New York, NY, USA, 2017; pp. 67-74.

35. Mariani, M.M.; Mura, M.; Di Felice, M. The determinants of Facebook social engagement for National Tourism Organisations Facebook pages: A quantitative approach. J. Destin. Mark. Manag. 2018, 8, 312-325. [CrossRef]

36. Saura, J.R.; Herraez, B.R.; Reyes-Menendez, A. Comparing a traditional approach for financial brand communication analysis with a big data analytics technique. IEEE Access 2019, 7, 37100-37108. [CrossRef]

37. Modi, D.; Zhao, L. Social media analysis of consumer opinion on apparel supply chain transparency. J. Fash. Mark. Manag. 2020. [CrossRef]

38. Lutfeali, S.; Ward, T.; Greene, T.; Arshonsky, J.; Seixas, A.; Dalton, M.; Bragg, M.A. Understanding the extent of adolescents' willingness to engage with food and beverage companies' instagram accounts: Experimental survey study. JMIR Public Health Surveill. 2020, 6, e20336. [CrossRef] [PubMed]

39. Denktaş-Şakar, G.; Sürücü, E. Stakeholder engagement via social media: An analysis of third-party logistics companies. Serv. Ind. J. 2020, 40, 866-889. [CrossRef]

40. Paliwoda-Matiolanska, A.; Smolak-Lozano, E.; Nakayama, A. Corporate image or social engagement: Twitter discourse on corporate social responsibility (CSR) in public relations strategies in the energy sector. Prof. Inf. 2020, 29, 1-16. [CrossRef]

41. Cuevas-Molano, E.; Sánchez Cid, M.; Matosas-López, L. Bibliometric analysis of studies of brand content strategy within social media. Comun. Soc. 2019, 2019, e7441. [CrossRef]

42. Phillips, L.; Dowling, C.; Shaffer, K.; Hodas, N.; Volkova, S. Using Social Media to Predict the Future: A Systematic Literature Review. Comput. Res. Repos. 2017, 2017, 1-55.

43. Matosas-López, L. Como gestionar de forma eficiente la presencia de empresas del sector del automóvil en twitter. La aplicación de algoritmos de aprendizaje automatizados para la categorización temática de publicaciones. In Proceedings of the Congreso para la Difusión de la Producción Científica e Investigadora, CODIPROCIN 2020, Madrid, Spain, 25 October 2020; Serrano Lozano, J., Ed.; AMEC Ediciones: Madrid, Spain, 2020; p. 22.

44. Interbrand Best Global Brands 2019; Interbrand: New York, NY, USA, 2019.

45. Alkadri, M.F.; Istiani, N.F.F.; Yatmo, Y.A. Mapping Social Media Texts as the Basis of Place-Making Process. Procedia-Soc. Behav. Sci. 2015, 184, 46-55. [CrossRef]

46. Quintana Pujalte, L.; Sosa Valcarcel, A.; Castillo Esparcia, A. Acciones y estrategias de comunicación en plataformas digitales. El caso Cifuentes. Prism. Soc. 2018, 22, 247-270.

47. Serrano, E.; Iglesias, C.A. Validating viral marketing strategies in Twitter via agent-based social simulation. Expert Syst. Appl. 2016, 50, 140-150. [CrossRef]

48. Hanifawati, T.; Ritonga, U.S.; Puspitasari, E.E. Managing brands' popularity on Facebook: Post time, content, and brand communication strategies. J. Indones. Econ. Bus. 2019, 34, 187-207. [CrossRef]

49. Hsu, B. Comparison of Supervised Classification Models on Textual Data. Mathematics 2020, 8, 851. [CrossRef]

50. Simeone, O. A Very Brief Introduction to Machine Learning with Applications to Communication Systems. IEEE Trans. Cogn Commun. Netw. 2018, 4, 648-664. [CrossRef]

51. Blachnik, M.; Kordos, M. Comparison of Instance Selection and Construction Methods with Various Classifiers. Appl. Sci. 2020, 10, 3933. [CrossRef]

52. Wang, Z.; Bai, G.; Chowdhury, S.; Xu, Q.; Seow, Z.L. Twilnsight: Discovering Topics and Sentiments from Social Media Datasets. Comput. Res. Repos. 2017, 2017, 1-14. 
53. Oviedo-García, M.A.; Muñoz-Expósito, M.; Castellanos-Verdugo, M.; Sancho-Mejías, M. Metric proposal for customer engagement in Facebook. J. Res. Interact. Mark. 2014, 8, 327-344. [CrossRef]

54. Matosas-López, L.; Romero-Ania, A. The Efficiency of Social Network Services Management in Organizations. An In-Depth Analysis Applying Machine Learning Algorithms and Multiple Linear Regressions. Appl. Sci. 2020, 10, 5167. [CrossRef]

55. Mohd Razali, N.; Bee Wah, Y. Power comparisons of Shapiro-Wilk, Kolmogorov-Smirnov, Lilliefors and Anderson-Darling tests. J. Stat. Model. Anal. 2011, 2, 21-33.

56. Gujarati, D.N.; Porter, D.C. Essentials of Econometrics, 4th ed.; McGraw-Hill: New York, NY, USA, 2010.

57. Matosas López, L. Variables of twitter's brand activity that influence audience spreading behavior of branded content. Esic Mark. Econ. Bus. J. 2018, 44, 525-546. [CrossRef]

58. Moro, S.; Rita, P.; Vala, B. Predicting social media performance metrics and evaluation of the impact on brand building: A data mining approach. J. Bus. Res. 2016, 69, 3341-3351. [CrossRef]

59. Soni, A.K. Multi-lingual sentiment analysis of Twitter data by using classification algorithms. In Proceedings of the 20172 nd IEEE International Conference on Electrical, Computer and Communication Technologies, ICECCT 2017, Coimbatore, India, 22-24 February 2017; Institute of Electrical and Electronics Engineers Inc.: Coimbatore, India, 2017.

60. Jiang, D.; Luo, X.; Xuan, J.; Xu, Z. Sentiment computing for the news event based on the social media big data. IEEE Access 2017, 5, 2373-2382. [CrossRef]

61. Alonso, M. Las redes sociales como canal de comunicación de las marcas de moda españolas. El caso de Zara, Mango y el Corte Inglés. Index Comun. 2015, 5, 77-105.

62. Laudano, C.N.; Planas, J.; Kessler, M.I. Aproximaciones a los usos de twitter en bibliotecas universitarias de Argentina. An. Doc. 2016, 19, 1-11. [CrossRef]

63. Sabate, F.; Berbegal-Mirabent, J.; Cañabate, A.; Lebherz, P.R. Factors influencing popularity of branded content in Facebook fan pages. Eur. Manag. J. 2014, 32, 1001-1011. [CrossRef]

64. Feng, C.; Fu, L.; Wu, X.; Gan, X.; Wang, X.; Chen, G.; Xu, J. Evolution Matters: Content Transmission in Evolving Wireless Social Networks. IEEE Trans. Wirel. Commun. 2020, 19, 7377-7391. [CrossRef]

65. Matosas-López, L. The Management of Digital Marketing Strategies in Social Network Services: A Comparison between American and European Organizations. J. Open Innov. Technol. Mark. Complex. 2021, 7, 65. [CrossRef]

66. Cuevas-Molano, E.; Matosas-López, L.; Bernal-Bravo, C. Factors Increasing Consumer Engagement of Branded Content in Instagram. IEEE Access 2021, 9, 143531-143548. [CrossRef]

67. Lou, C.; Tan, S.S.; Chen, X. Investigating Consumer Engagement with Influencer- vs. Brand-Promoted Ads: The Roles of Source and Disclosure. J. Interact. Advert. 2019, 19, 169-186. [CrossRef] 